\title{
On prefermentative maceration techniques: statistical analysis of sensory descriptors in Sangiovese wine
}

\author{
Alessandro Magrini ${ }^{1}$, Ottorino L. Pantani ${ }^{2}$, Alessandra Biondi Bartolini ${ }^{3}$ \\ Federico M. Stefanini ${ }^{1}$
${ }^{1}$ Department of Statistics, Computer Science, Applications, University of Florence, Italy, e-mail: stefanini@disia.unifi.it
${ }^{2}$ Department of Soil Vegetation and Forest Environment, University of Florence, Italy
${ }^{3} \mathrm{R} \& \mathrm{D}$ wine and sensory consultant

\begin{abstract}
SUMMARY
The analysis of wine sensory descriptors is a fundamental step in the improvement of wine making, because the procedures are judged just before bottled wine is ready for consumption. Despite several contributions in the literature, traditional analysis of variance methods are not adequate to analyse sensory descriptors, because they are defined on ordinal scales. In this paper, we exploit cumulative link mixed models in a three-way full factorial design to assess the effect of prefermentative maceration, temperature and saignée on wine sensory descriptors. Using cumulative link mixed models, the bias introduced by assessors' judgement and the ordinal scale of sensory descriptors are taken into account. The results were the following: the application of prefermentative maceration techniques did not lead to an improvement in the sensory profile of wines after a year from bottling; wines treated with saignée showed greater intensity in olfactive descriptors; and higher fermentation temperatures resulted in wines that were generally more concentrated.
\end{abstract}

Key words: cumulative link mixed models, proportional odds, assessor bias, cold soak prefermentative maceration, cryomaceration.

\section{Introduction}

The final effect of different vinification procedures may be investigated by measuring changes in the chemical compounds related to colour and flavours over time, but the relevance of the hedonistic aspect of wine motivates sensory evaluations to characterise vinification procedures in terms of perceived quality. Descriptive sensory analysis is particularly suited for this purpose (Murray, 
2001; Lesschaeve, 2007): a panel of assessors provides an evaluation of several sensory descriptors; a new vinification procedure is declared effective if statistically significant changes in one or more descriptors are detected with respect to the traditional procedure.

This study considers Sangiovese wine making using grapes from Tuscany (2008 vintage). A three-way full factorial design with three replications is investigated to assess the effect of three factors on wine quality:

- prefermentative maceration techniques: standard fermentation (CTRL), cold soak prefermentation (CSPF), cryomaceration (CRYO);

- temperature of fermentation: $20^{\circ} \mathrm{C}(\mathrm{t} 20), 30^{\circ} \mathrm{C}(\mathrm{t} 30)$;

- saignée: absent (noS), present (yeS).

The design encompasses 12 different vinification procedures (treatments), for a total of 36 vinifications. Eight olfactive and six gustative and tactile descriptors were evaluated on a four-level hedonistic scale, one year after bottling. In order to reduce both the costs and time needed to train assessors, sensory evaluation was performed by an ad-interim panel formed by people involved in the experiment, as suggested by Lesschaeve (2007).

Several studies in the literature use traditional analysis of variance (ANOVA) methods to analyse sensory descriptors (Runnebaum et al., 2011; Carlucci and Monteleone, 2008; Etaio et al., 2008; Parenti et al., 2004; Marais, 2003; Lawless et al., 1997). However, ANOVA is not adequate because, even if one can safely assume that the intervals between categories of the descriptors are equal, residuals are not normally distributed and homoscedasticity may not hold. Here, we exploit cumulative link mixed models in order to take into account the ordinal scale of sensory descriptors and the bias introduced by assessors' judgement.

In section 2 the experimental setup is described. In section 3 we provide details on panel formation, training and evaluation sessions. The statistical analysis is detailed in section 4 . In section 5 the results are presented, and the findings are discussed in section 6 . 


\section{Experimental setup}

Sangiovese grapes from the area of Maremma, South Tuscany, were manually harvested at maturity (2008 vintage) and collected in $20 \mathrm{~kg}$ buckets. A randomisation procedure was used to allocate the buckets within bins (500 1 each), which were transported to the experimental winery and randomly assigned to vinification tanks (1000 1 each, stainless steel). A wine cellar was prepared to host the experiment (http://www.ricercatuscania.it). A programmable control unit (Parsec s.r.l.C2007) regulated the temperatures and pumping-overs of each individual tank.

The destemmed and crushed berries destined for standard fermentation were sent directly to the tanks and brought to the planned fermentation temperature. Cold soak prefermentation was applied by lowering the temperature to $5^{\circ} \mathrm{C}$ immediately after filling the tanks; this temperature was maintained for 48 hours. Cryomaceration was performed on the destemmed and drained berries using an experimental apparatus (Parsec s.r.1.@2007) consisting of a freezing tunnel containing a stainless steel conveyor belt, on top of which liquid nitrogen sprinklers were installed. The contact time of liquid nitrogen with the berries was approximately 5-10 seconds, such that the final temperature of the mass was below $0^{\circ} \mathrm{C}$, as regulated by the speed of the conveyor belt. The temperature of the flowing mass was measured and found to be between $+7^{\circ} \mathrm{C}$ and $-5^{\circ} \mathrm{C}$. The cryomacerated berries were then crushed and added to the previously drained must.

Saignée was applied by bleeding off $200 \mathrm{~kg}$ must from the bottom valve of each tank, immediately after filling, so that the tank volume was the same as for the other ferments. Each tank was then supplemented with potassium metabisulphite $(50 \mathrm{mg} / \mathrm{l})$ and the temperature was set at the appropriate level $\left(20^{\circ} \mathrm{C}\right.$ or $\left.30^{\circ} \mathrm{C}\right)$. Finally, the tanks were inoculated with $250 \mathrm{mg} / 1$ of EC1118 Lalvin ${ }^{\circledR}$ yeast strain. CRYO tanks were inoculated once the temperature reached $20^{\circ} \mathrm{C}(18-24 \mathrm{~h})$. During the maceration, which lasted for 14 days, 
the tanks underwent pumping-over cycles, whose number and duration were adjusted daily on the basis of the must density.

A comprehensive description of the wine-making process is provided in Pantani et al. (2014).

\section{Panel formation, training and evaluation sessions}

The effect of the tested treatments on sensory descriptors was evaluated following a descriptive approach (Marais, 2003). For this purpose, a panel of tasters was formed and trained. The panel consisted of people involved in the experiment, including wine experts, winemakers and a non-expert wine taster.

The training activity consisted of six sessions in which assessors were trained to identify a descriptor in a genuine standard and in wine; they were then trained to identify and sort different concentrations of gustatory standards in water and in wine. Finally, they were taught to describe red wines' gustatory and tactile sensations, as provided by Delteil (2000) and by Granes et al. (2009) for the ASDQ method developed by ICV (Institute Cooperative du Vin, Lattes, France).

A descriptive evaluation card was specifically developed for this study, where visual, olfactive, gustatory and tactile descriptors were considered. The visual properties were synthesised in one descriptor: the perceived colour intensity. Olfactory descriptors were chosen according to the method of the Free Choice Profile: five wines randomly chosen among those included in the experiment were submitted to the assessors, who provided olfactory sensations using their own words. Those olfactory descriptions were later discussed in a round table, to determine an unambiguous association between common semantic labels and personal perceived sensations.

Eight olfactive descriptors were finally agreed upon and included in the card: 'Fruity' (berries and tree fruit), 'Preserved Fruit', 'Spicy', 'Vegetal', 'Caramel' (candy), 'Chemical', 'Reductive Flavour' and 'Acetaldehyde' (bruised apple). Gustative and tactile profiles were assessed by means of the following six 
descriptors: 'Volume', 'Acidity', 'Tannic Intensity', 'Astringency', 'Dryness' and 'Bitterness' (Delteil, 2000).

For each sensory descriptor, a four-level hedonistic scale was defined. The sensory evaluation was performed 12 months after wine bottling. All wines were tasted in three weekly sessions of panel testing. In each session, a sample from all treatments of one of the three replications (12 samples) was submitted to the panel of assessors in two series of six tastings, each separated from the other by a break of 20 minutes in order to reduce the potential bias due to fatigue (Bajec and Pickering, 2008). In the evaluation, descriptors were considered sequentially: the first three were evaluated when the wine was in the mouth, while the last three were evaluated after expelling the wine from the mouth. Bottles were taken from a stock kept at $18-20^{\circ} \mathrm{C}$, a suitable temperature range for the serving of red wines. Samples were anonymised by assigning a threedigit numerical label and submitted for tasting in a random order.

\section{Statistical analysis}

A sensory descriptor is an ordinal variable that may take $J>2$ different values, indicated by numerical values $j=1, \ldots, J$ called scores. Each treatment is coded by a configuration $\boldsymbol{x}$ of 11 dummy variables:

$$
\begin{aligned}
& \boldsymbol{x}=\left(\boldsymbol{x}_{\mathrm{CSPF}}, \boldsymbol{x}_{\mathrm{CRYO}}, \boldsymbol{x}_{\mathrm{t} 20}, \boldsymbol{x}_{\mathrm{yeS}}, \boldsymbol{x}_{\mathrm{CSPF}: \mathrm{t} 30}, x_{\mathrm{CSPF}: \mathrm{yeS}}, x_{\mathrm{CRYO}: \mathrm{t} 30}, x_{\mathrm{CRYO}: \mathrm{yeS}},\right. \\
& \left.\boldsymbol{x}_{\mathrm{t} 30: \mathrm{yeS}}, \boldsymbol{x}_{\mathrm{CSPF}: \mathrm{t} 30: \mathrm{yeS},}, \boldsymbol{x}_{\mathrm{CRYO}: \mathrm{t30}: \mathrm{yeS}}\right)
\end{aligned}
$$

as shown in Table 1. Note that the treatment CTRL_t20_noS is taken as the reference due to its having the mildest vinification conditions; thus it is coded by a vector of zeros.

In this section, we provide technical details on cumulative link mixed models (subsection 4.1), discuss the interpretation of parameters representing the effect of the tested treatments (4.2), and explain the method used to quantify the statistical significance of each main effect and interaction term (4.3). 


\subsection{Cumulative link mixed models}

Cumulative link mixed models were developed by Hedeker and Gibbons (1994) and by Tutz and Hennevogl (1996) by extending ordinal logit (proportional odds) models to clustered or longitudinal data. A cumulative link mixed model for a generic sensory descriptor $Y$ has the following form:

$$
\begin{aligned}
& G^{-1}\left(\operatorname{Pr}\left[Y \leq j \mid \boldsymbol{x}, \delta_{k}\right]\right)=\eta_{j}+\delta_{k}-\boldsymbol{x}^{\prime} \boldsymbol{\beta} \\
& \delta_{k} \stackrel{\text { i.i.d. }}{\sim} \mathrm{N}\left(0, \sigma_{\delta}^{2}\right), j=1, \ldots, J, k=1, \ldots, K
\end{aligned}
$$

where $G^{-1}(\pi)=\log (\pi /(1-\pi))$ is the quantile function of the standard logistic distribution, often called logit link; $\eta_{j}$ is an intercept depending on the score under consideration (the $j$-th); $\delta_{k}$ is a random effect depending on the assessor under consideration (the $k$-th); and $\boldsymbol{\beta}$ is a vector of parameters, one for each of the 11 dummy variables encoding the tested treatments. This model is a linear regression where the response is the logit transformation of the cumulative probability for each score. The minus sign before $\boldsymbol{x}^{\prime} \boldsymbol{\beta}$ is introduced so that a positive value of any parameter implies a greater probability for higher scores. Note that the parameters in $\boldsymbol{\beta}$ do not depend either on the score, or on the assessor. See Agresti (2002, Chapter 7) for further details.

\begin{tabular}{|c|c|c|c|}
\hline $\begin{array}{l}\text { Prefermentative } \\
\text { maceration }\end{array}$ & Temperature & Saignée & $\begin{array}{c}\text { Code } \\
\text { of the treatment }\end{array}$ \\
\hline CTRL & & \multirow{6}{*}{ noS } & $(0,0,0,0,0,0,0,0,0,0,0)$ \\
\hline CSPF & t20 & & $(1,0,0,0,0,0,0,0,0,0,0)$ \\
\hline CRYO & & & $(0,1,0,0,0,0,0,0,0,0,0)$ \\
\hline CTRL & \multirow{3}{*}{$\mathrm{t} 30$} & & $(0,0,1,0,0,0,0,0,0,0,0)$ \\
\hline CSPF & & & $(1,0,1,0,1,0,0,0,0,0,0)$ \\
\hline CRYO & & & $(0,1,1,0,0,1,0,0,0,0,0)$ \\
\hline CTRL & \multirow{3}{*}{$\mathrm{t} 20$} & \multirow{6}{*}{ yes } & $(0,0,0,1,0,0,0,0,0,0,0)$ \\
\hline CSPF & & & $(1,0,0,1,0,0,1,0,0,0,0)$ \\
\hline CRYO & & & $(0,1,0,1,0,0,0,1,0,0,0)$ \\
\hline CTRL & \multirow{3}{*}{$\mathrm{t} 30$} & & $(0,0,1,1,0,0,0,0,1,0,0)$ \\
\hline CSPF & & & $(1,0,1,1,1,0,1,0,1,1,0)$ \\
\hline CRYO & & & $(0,1,1,1,0,1,0,1,1,0,1)$ \\
\hline
\end{tabular}

Table 1. Codes of the tested treatments 


\subsection{Interpretation of parameters}

Consider the odds of the event $Y>j$ given treatment $\boldsymbol{x}$ and assessor $k$ defined as:

$$
\left.\operatorname{odds}\left[Y>j \mid \boldsymbol{x}, \delta_{k}\right]\right)=\frac{\operatorname{Pr}\left[Y>j \mid \boldsymbol{x}, \delta_{k}\right]}{\operatorname{Pr}\left[Y \leq j \mid \boldsymbol{x}, \delta_{k}\right]}
$$

For example, if the event $Y>j$ has probability $1 / 6$, then its odds are $1 / 5$. An odds ratio is the ratio of the odds for the same score and assessor under two different treatments, say $\boldsymbol{x}_{1}$ and $\boldsymbol{x}_{2}$ :

$$
\left.\mathrm{OR}\left[Y>j \mid \boldsymbol{x}_{1}, \boldsymbol{x}_{2}, \delta_{k}\right]\right)=\frac{\operatorname{Pr}\left[Y>j \mid \boldsymbol{x}_{2}, \delta_{k}\right] / \operatorname{Pr}\left[Y \leq j \mid \boldsymbol{x}_{2}, \delta_{k}\right]}{\operatorname{Pr}\left[Y>j \mid \boldsymbol{x}_{1}, \delta_{k}\right] / \operatorname{Pr}\left[Y \leq j \mid \boldsymbol{x}_{1}, \delta_{k}\right]}
$$

For example, an odds ratio equal to 2 implies that, by applying the treatment $\boldsymbol{x}_{2}$, the odds of the event $Y>j$ are expected to be twice the odds obtained applying the treatment $\boldsymbol{x}_{1}$.

The effect of the tested treatments is assessed by computing the odds ratio between each treatment and the reference. If the odds ratio is 1 , there is no difference between the treatment considered and the reference treatment. If the odds ratio is greater (lower) than 1 , the treatment considered is expected to provide higher (lower) response scores than the reference. In a cumulative link mixed model, the odds ratio between a generic treatment $\boldsymbol{x}$ and the reference treatment $\boldsymbol{x}_{0}$ for score $j$ and assessor $k$ is:

$$
\begin{aligned}
& \left.\mathrm{OR}\left[Y>j \mid \boldsymbol{x}_{0}, \boldsymbol{x}, \delta_{k}\right]\right)=\frac{\operatorname{Pr}\left[Y>j \mid \boldsymbol{x}, \delta_{k}\right] / \operatorname{Pr}\left[Y \leq j \mid \boldsymbol{x}, \delta_{k}\right]}{\operatorname{Pr}\left[Y>j \mid \boldsymbol{x}_{0}, \delta_{k}\right] / \operatorname{Pr}\left[Y \leq j \mid \boldsymbol{x}_{0}, \delta_{k}\right]}= \\
& =\frac{\exp \left(\eta_{j}+\delta_{k}-\boldsymbol{x}^{\prime} \boldsymbol{\beta}\right)}{\exp \left(\eta_{j}+\delta_{k}-\boldsymbol{x}_{0}^{\prime} \boldsymbol{\beta}\right)}=\exp \left(\boldsymbol{x}^{\prime} \boldsymbol{\beta}\right)
\end{aligned}
$$

that is, it is the same for each score and for each assessor.

\subsection{Analysis of deviance}

The statistical significance of each main effect and interaction term is quantified by comparing the deviance of the reduced models obtained by constraining the 
parameters in $\boldsymbol{\beta}$ of the model in Equation 1 to the value 0 . Any reduced model obtained in this way is coded by a set of dummy variables similarly to the treatments: the value 0 indicates that a parameter is constrained to 0 , and the value 1 indicates that a parameter is freely estimated. The deviance explained by a main effect or an interaction term is given by the difference in the deviance between the reduced model with the minimum number of parameters including that main effect or interaction, say $\mathcal{M}_{1}$, and the reduced model obtained from $\mathcal{M}_{1}$ by constraining the regression coefficients associated with that main effect or interaction to the value 0 , say $\mathcal{M}_{0}$. Table 2 shows the codes of the reduced models that are to be compared in order to compute the deviance explained by each main effect and interaction term. The deviance between $\mathcal{M}_{1}$ and $\mathcal{M}_{0}$ is tested by considering that the log-likelihood ratio statistic:

$$
\mathcal{D}_{\mathcal{M}_{1} \mid \mathcal{M}_{0}}=-2\left(l_{\mathcal{M}_{1}}-l_{\mathcal{M}_{0}}\right)
$$

is asymptotically distributed as a $\chi^{2}$ random variable with a number of degrees of freedom equal to the difference in the number of parameters between $\mathcal{M}_{1}$ and $\mathcal{M}_{0}$, where $l_{\mathcal{M}_{1}}$ and $l_{\mathcal{M}_{0}}$ are, respectively, the log-likelihood of models $\mathcal{M}_{1}$ and $\mathcal{M}_{0}$ computed at the maximum likelihood estimates of parameters.

Further deviance terms may be considered: the deviance explained by the heterogeneity in the assessors' judgement, which is computed by comparing the reduced model where $\sigma_{\delta}^{2}=0$ with the model in Equation 1; and the residual deviance, which is obtained by comparing the model in Equation 1 with the model having one parameter per observation (saturated model).

An estimation of the odds ratio for the generic treatment $\boldsymbol{x}$ with respect to the reference treatment is obtained as $\exp \left(\boldsymbol{x}^{\prime} \widehat{\boldsymbol{\beta}}\right)$, where $\widehat{\boldsymbol{\beta}}$ is the maximum likelihood estimate of $\boldsymbol{\beta}$. An asymptotic $95 \%$ confidence interval for the odds ratio of $\boldsymbol{x}$ is:

$$
\left(\exp \left(\boldsymbol{x}^{\prime} \widehat{\boldsymbol{\beta}}\right)-1.96 \sqrt{\boldsymbol{x}^{\prime} \widehat{\boldsymbol{S}} \boldsymbol{x}}, \exp \left(\boldsymbol{x}^{\prime} \widehat{\boldsymbol{\beta}}\right)+1.96 \sqrt{\boldsymbol{x}^{\prime} \widehat{\boldsymbol{S}} \boldsymbol{x}}\right)
$$

where $\widehat{\boldsymbol{S}}$ is the estimated variance and covariance matrix of $\widehat{\boldsymbol{\beta}}$. 
Table 2. Codes of reduced models to be compared in order to compute the deviance explained by each main effect and interaction term. 'macer': prefermentative maceration; 'temp': temperature of fermentation; 'df': degrees of freedom of the loglikelihood ratio statistic. Colons indicate interactions between experimental factors

\begin{tabular}{cccc}
\hline & $\mathcal{M}_{1}$ & $\mathcal{M}_{0}$ & $\mathrm{df}$ \\
\hline macer & $(1,1,0,0,0,0,0,0,0,0,0)$ & $(0,0,0,0,0,0,0,0,0,0,0)$ & 2 \\
temp & $(0,0,1,0,0,0,0,0,0,0,0)$ & $(0,0,0,0,0,0,0,0,0,0,0)$ & 1 \\
saignée & $(0,0,0,1,0,0,0,0,0,0,0)$ & $(0,0,0,0,0,0,0,0,0,0,0)$ & 1 \\
macer:temp & $(1,1,1,0,1,1,0,0,0,0,0)$ & $(1,1,1,0,0,0,0,0,0,0,0)$ & 2 \\
macer:saignée & $(1,1,0,1,0,0,1,1,0,0,0)$ & $(1,1,0,1,0,0,0,0,0,0,0)$ & 2 \\
temp:saignée & $(0,0,1,1,0,0,0,1,0,0,0)$ & $(0,0,1,1,0,0,0,0,0,0,0)$ & 1 \\
macer:temp:saignée & $(1,1,1,1,1,1,1,1,1,1,1)$ & $(1,1,1,1,1,1,1,1,1,0,0)$ & 2 \\
\hline
\end{tabular}

\section{Results}

The statistical analysis was performed using the function clmm contained in the $\mathrm{R}$ package ordinal (Christensen, 2015). Wine characteristics found to be significantly affected by at least one experimental factor include the visual descriptor 'Colour', the olfactive descriptors 'Fruity', 'Spicy', 'Reductive Flavour', and the gustative and tactile descriptors 'Volume', 'Tannic Intensity', 'Astringency', 'Dryness'. The descriptors 'Preserved fruit', 'Vegetable', 'Candy', 'Chemical', 'Bruised 'Apple', 'Acidity' and 'Bitterness' were found not to be significantly affected by any experimental factors. The analysis of deviance for sensory descriptors which were significantly affected by at least one experimental factor is shown in Table 3. A summary of the parameter estimation for each sensory descriptor is given in the Appendix.

\subsection{Evaluation of treatments}

Table 4 shows estimated odds ratios for each treatment concerning sensory descriptors which were found to be significantly affected by at least one experimental factor (reference treatment: CTRL_t20_noS). 
Table 3. Analysis of deviance tables for sensory descriptors found to be significantly affected by at least one experimental factor. 'macer': prefermentative maceration; 'temp': temperature of fermentation; 'df': degrees of freedom of the log-likelihood ratio statistic. Colons indicate interactions between experimental factors. ' $*$ ': statistically significant at the level 0.05 ; '**': statistically significant at 0.01 ; ‘***': statistically significant at 0.001

\begin{tabular}{lccccc}
\hline Source & df & Colour & Fruity & Spicy & Reductive Flavour \\
\hline assessors & 1 & $118.59 * * *$ & $92.37 * * *$ & $198.74 * * *$ & $47.81 * * *$ \\
macer & 2 & 4.30 & 2.52 & 0.42 & 3.22 \\
Temp & 1 & $51.62 * * *$ & 2.49 & $2.91 * *$ & $7.32 * *$ \\
saignée & 1 & $21.38 * * *$ & $5.76 *$ & 1.18 & $5.89 *$ \\
macer:temp & 2 & 4.20 & 2.84 & 1.67 & 2.23 \\
macer:saignée & 2 & 1.34 & 2.51 & 1.50 & 1.89 \\
temp:saignée & 1 & 1.94 & 0.03 & $5.17 * * *$ & 0.41 \\
macer:temp:saignée & 2 & $17.35 * * *$ & 3.42 & 0.78 & $8.32 *$ \\
residuals & 24 & 96.91 & 26.81 & 21.36 & 25.96 \\
& & & & & Astringency \\
\hline Source & df & Volume & Tannic Intensity & $79.69 * * *$ & $88.83 * * *$ \\
assessors & 1 & $149.90 * * *$ & $173.79 * * *$ & 1.64 & 1.69 \\
macer & 2 & 5.29 & 0.19 & $5.05 *$ & $7.87 * *$ \\
temp & 1 & $10.49 * *$ & $11.95 * * *$ & 0.25 & 0.46 \\
saignée & 1 & 0.13 & 1.63 & 2.53 & 5.05 \\
macer:temp & 2 & 0.20 & 0.39 & 2.82 & 1.40 \\
macer:saignée & 2 & 0.02 & 0.63 & 0.23 & 1.76 \\
temp:saignée & 1 & 2.87 & 0.23 & 2.12 & 1.46 \\
macer:temp:saignée & 2 & 3.18 & 2.90 & 18.26 & 15.93 \\
residuals & 24 & 28.31 & 28.40 & &
\end{tabular}

The application of saignée entails a significantly positive effect on the descriptor 'Fruity', as shown by the estimated odds ratio of 3.16. This means that the odds for 'Fruity' to be rated with higher scores in wines treated only with saignée (CTRL_t20_yeS) are more than one-and-a-half times the odds for wines not so treated (CTRL_t20_noS). Similar results were found for the descriptors 'Colour' (odds ratio 1.39) and 'Reductive Flavour' (odds ratio 7.03).

Conversely, wines fermented at $30^{\circ} \mathrm{C}$ were rated significantly higher in the perception of 'Colour' (odds ratio 15.46), 'Reductive Flavour' (odds ratio 1.61), 'Volume' (odds ratio 1.88), 'Tannic Intensity' (odds ratio 2.71), 'Dryness' (odds ratio 1.43) and 'Astringency' (odds ratio 1.9) than wines fermented at $20^{\circ} \mathrm{C}$. On the other hand, the higher temperature of fermentation resulted in lower 

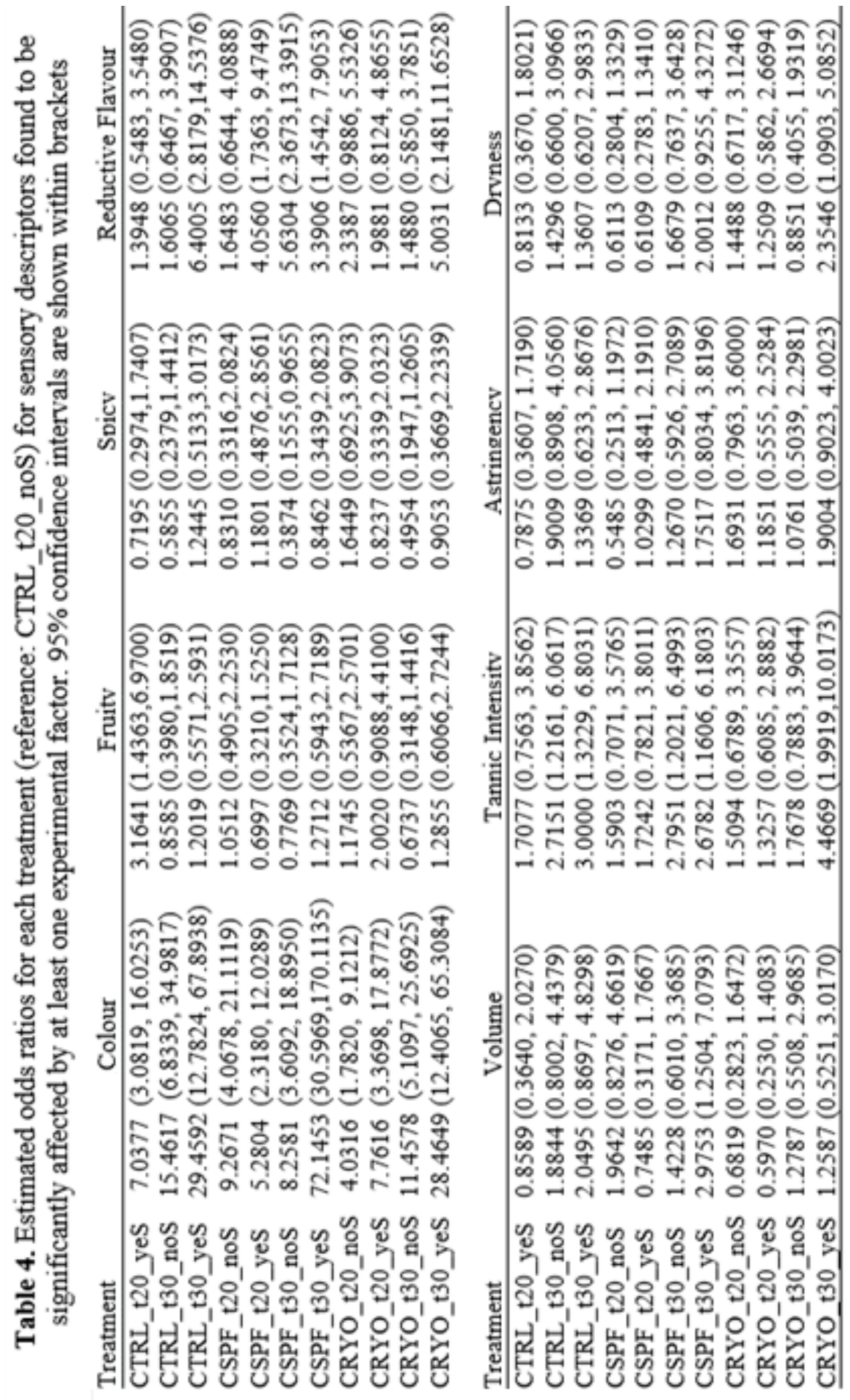


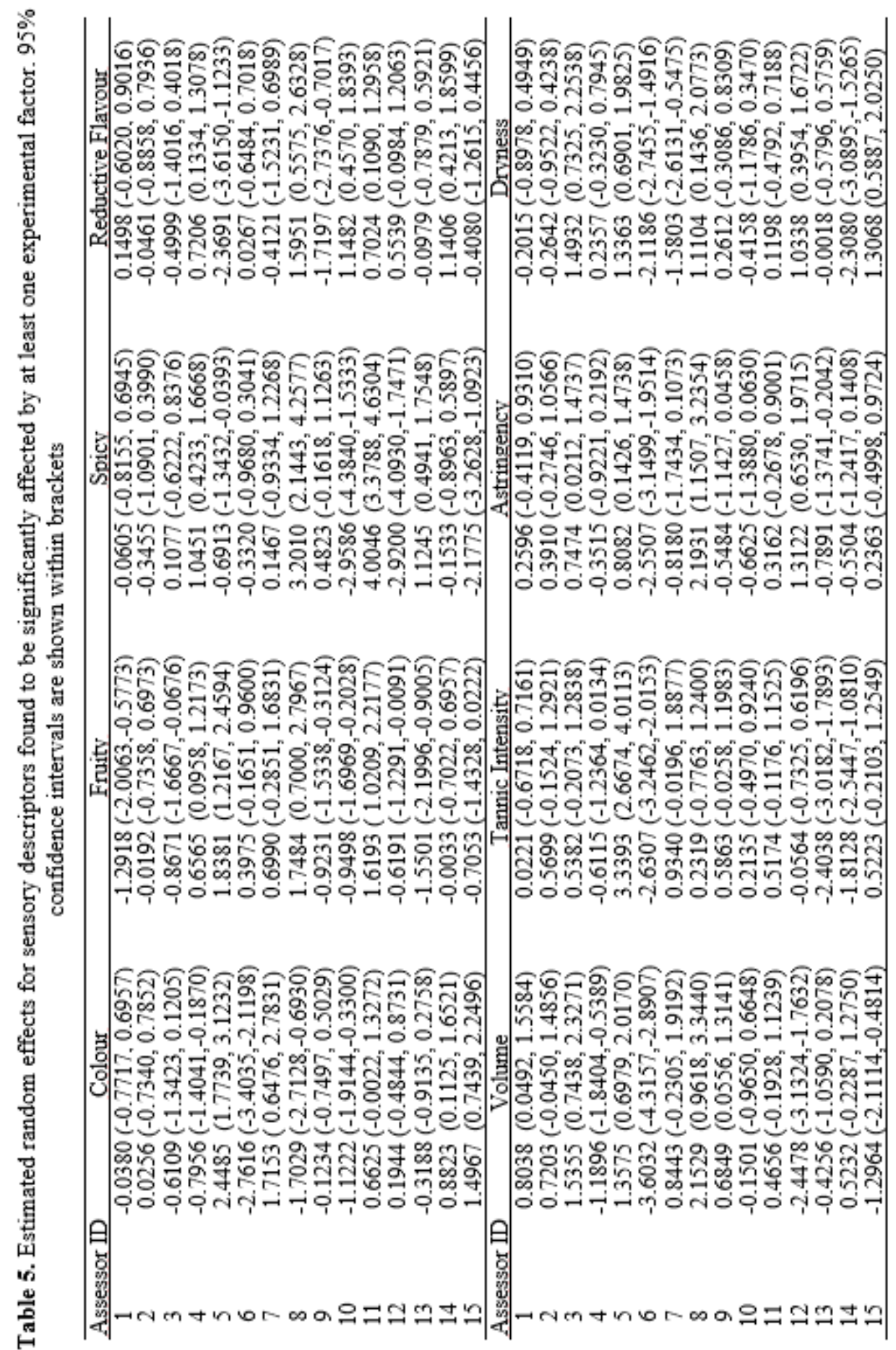


perceptions of the descriptor 'Spicy' (odds ratio 0.58). In particular, the (negative) effect was larger if saignée was also applied (odds ratio 0.72).

The full-order interaction proved to be significant for the descriptors 'Colour' and 'Reductive Flavour'. The effect of joint application of $30^{\circ} \mathrm{C}$ fermentation and saignée on the descriptor 'Colour' was greater if cold soak prefermentation was applied (odds ratio 72.14 against 29.46). On the other hand, the effect of joint application of $30^{\circ} \mathrm{C}$ fermentation and saignée on the descriptor 'Reductive Flavour' was lower if cold soak prefermentation or cryomaceration was applied (odds ratios 3.39 and 5.00 against 6.40).

\subsection{Evaluation of heterogeneity in assessors' judgement}

For each sensory descriptor, random effects quantify the deviation of the assessors' judgement from the 'average' opinion $\left(\delta_{k}=0\right)$. Since random effects do not depend either on the response score or on the treatment, the cumulative link mixed model makes it possible to separate the heterogeneity in the assessors' judgement from the effect of the tested treatments.

Table 5 shows estimated random effects for sensory descriptors which were found to be significantly affected by at least one experimental factor. The heterogeneity in the assessors' judgements was confirmed by the significance of the deviance explained by random effects (see Table 3 ).

The bias introduced by each assessor may be quantified in terms of the deviation of the respective random effect from value 0 , which corresponds to the random effect of the 'average' assessor. Although random effects were ranked differently across sensory descriptors, it is apparent that some assessors tended to award higher scores than the average (numbers 6,10 and 13), while others had the opposite tendency (numbers 5, 8 and 11). Assessors 1, 2 and 3 were close to the 'average' value for each wine descriptor.

Two natural interpretations of the heterogeneity in the assessors' judgement are either that each score means different things to different assessors, or that assessors have a different perception of the same sensory descriptor. 


\section{Discussion}

A descriptive sensory approach was adopted to evaluate the effect of different fermentation techniques on Sangiovese quality after one year from bottling, including cold soak prefermentation, cryomaceration, $30^{\circ} \mathrm{C}$ temperature and saignée. For this purpose, an ad-interim panel was formed by people involved in the experiment (15 assessors). The analysis was performed using cumulative link mixed models, in order to take into account the ordinal scale of sensory descriptors and bias in assessors' judgement: on one hand, a linear regression model is applied to the logit of the cumulative probability of each score, instead of to the score itself; on the other hand, a random effect is estimated for each assessor.

Wines treated with saignée resulted in a greater intensity in the descriptors 'Colour' and 'Fruity'. However, the descriptor 'Reductive Flavour' was also found to be significantly affected by saignée, suggesting that the treatment should be applied carefully. It is noteworthy that the increase in the score for 'Reductive Flavour' can be prevented by applying cold soak prefermentation or cryomaceration.

Higher fermentation temperatures resulted in greater expression of all of the gustatory descriptors except for 'Fruity', that is in wines with a highly concentrated profile. However, we must consider that some assessors might perceive high scores for the descriptor 'Dryness' as a depreciation of wine quality.

The application of prefermentative maceration techniques did not lead to an improvement in the sensory profile of wines after a year from bottling, but it amplified the effect of the joint application of $30^{\circ} \mathrm{C}$ fermentation and saignée on the visual descriptor 'Colour', while also preventing the increase in the score for 'Reductive Flavour'. The lack of a main effect due to prefermentative maceration techniques is in contrast with the results of related studies performed on wines drawn earlier. For instance, Marais (2003) reported a marked effect of cold soak prefermentation on the overall quality of Pinotage after six months 
from bottling (on 'Fruity', in particular), while Parenti et al. (2004) found an increase in 'Colour', 'Tannic Intensity' and 'Astringency' for cryomacerated Sangiovese after two months from bottling. In our study, the wines were tasted far later (one year from bottling); we therefore believe that the differences in the results are due to the rapid loss of these quality characteristics in the first months after bottling.

Random effects made it possible not only to characterise each assessor with respect to the bias introduced in his or her judgements, but also to individuate assessors with a definite tendency in awarding scores lower than, higher than or close to the average. Furthermore, estimated random effects could be useful in developing ad-hoc training for each assessor before future sessions.

\section{Acknowledgements}

This study was part of a research project funded by the Italian Ministry of Economic Development and Consorzio Tuscania, Florence, Italy

(http://www.ricercatuscania.it).

\section{REFERENCES}

Agresti A. (2002): Categorical data analysis. Second edition. Wiley.

Bajec M.R., Pickering G.J. (2008): Astringency: mechanisms and perception critical reviews. Food Science and Nutrition 48(9): 858-875.

Carlucci A., Monteleone E. (2008): A procedure of sensory evaluation for describing the aroma profile of single grape variety vines. Journal of Sensory Studies 23(6): 817-834.

Christensen R.H.B. (2015): ordinal: regression models for ordinal data. R package version 2015-06-28. http://www.cran.r-project.org/package=ordinal

Delteil D. (2000): Evaluation sensorielle du profil gustatif des vins. Revue des Oenologues 94: 21-23.

Etaio I., Pérez Elortondo F.J., Albisu M., Gaston E., Ojeda M., Schlich P. (2008): Development of a quantitative sensory method for the description of young red wines from Rioja Avalesa. Journal of Sensory Studies 23(5): 631-655.

Hedeker D., Gibbons R.D. (1994): A random-effects ordinal regression model for multilevel analysis. Biometrics 50(4): 933-944.

Lawless H., Liu Y., Goldwyn C. (1997): Evaluation of wine quality using a smallpanel hedonic scaling method. Journal of Sensory Studies 12(4): 317-322. 
Granes D., Pic-Blateyron L., Negrel J., Bonnefond C. (2009): L'analyse sensorielle descriptive quantifie (ASDQ): une methode pour un langage commun. Revue Francaise d'Oenologie 238: 16-21.

Lesschaeve I. (2007): Sensory evaluation of wine and commercial realities: review of current practices and perspectives. American Journal of Enology and Viticulture 58: $252-258$.

Marais J. (2003): Effect of different wine-making techniques on the composition and quality of Pinotage wine. I. Low temperature skin contact prior to fermentation quadrature. South African Journal for Enology and Viticulture 24: 70-75.

Murray J.M., Delahunty C.M., Baxter I.A. (2001): Descriptive sensory analysis: past, present and future. Food Research International 34: 461-471.

Pantani O.L., Stefanini F.M., Lozzi I., Calamai L., Biondi Bartolini A., Di Blasi S. (2014): Pre-maceration, saignée and temperature affect daily evolution of pigment extraction during vinification. COBRA Preprint Series, Working Paper 107. http://biostats.bepress.com/cobra/art107

Parenti A., Spugnoli P., Calamai L., Ferrari S., Gori C. (2004): Effects of cold maceration on red wine quality from Tuscan Sangiovese grape. European Food Research and Technology 218: 360-366.

Runnebaum R.C., Boulton R.B., Powell R.L., Heymann H. (2011): Key constituents affecting wine body - an exploratory study. Journal of Sensory Studies 26: 6270.

Tutz G., Hennevogl W. (1996): Random effects in ordinal regression models. Computational Statistics and Data Analysis 2: 537-557.

\section{Appendix}

Response: Colour
(Intercept $1 \mid 2)$
(Intercept $2 \mid 3)$
(Intercept $3 \mid 4)$
macer_mpf
macer_crio
temp_t30
saignée_yeS
macer_mpf:temp_t30
macer_crio:temp_t30
macer_mpf:saignée_yeS
macer_crio:saignée_yeS
temp_t30:saignée_yeS
macer_mpf:temp_t30:saignée_yeS
macer_crio:temp_t30:saignée_yeS
Variance of random effects: $\mathbf{1 . 8 4 5 6 6 7}$
Log-likelihood: -406.2734 AIC: $\mathbf{8 4 2 . 5 4 6 7}$

$\begin{array}{llll}\text { Estimate } & \text { Std. Error } & \boldsymbol{z} \text { value } & \boldsymbol{p} \text { value } \\ -1.5487 & 0.5232 & -2.9599 & 0.0031 \\ 1.2612 & 0.5181 & 2.4342 & 0.0149 \\ 4.3539 & 0.5570 & 7.8167 & 0.0000 \\ 2.2265 & 0.5069 & 4.3923 & 0.0000 \\ 1.3942 & 0.4967 & 2.8067 & 0.0050 \\ 2.7384 & 0.5099 & 5.3708 & 0.0000 \\ 1.9499 & 0.5051 & 3.8607 & 0.0001 \\ -2.8536 & 0.6995 & -4.0796 & 0.0000 \\ -1.6939 & 0.6815 & -2.4854 & 0.0129 \\ -2.5123 & 0.6979 & -3.6001 & 0.0003 \\ -1.2948 & 0.6912 & -1.8732 & 0.0610 \\ -1.3052 & 0.6928 & -1.8840 & 0.0596 \\ 4.0352 & 0.9894 & 4.0784 & 0.0000 \\ 1.5602 & 0.9639 & 1.6186 & 0.1055\end{array}$


Response: Fruity

(Intercept 1|2)

(Intercept 2|3)

(Intercept 3|4)

macer_mpf

macer_crio

temp_t30

saignée_yeS

macer_mpf:temp_t30

macer_crio:temp_t30

macer_mpf:saignée_yeS

macer_crio:saignée_yeS

temp_t30:saignée_yeS

macer_mpf:temp_t30:saignée_yeS

macer_crio:temp_t30:saignée_yeS

Variance of random effects: 1.318172

Log-likelihood: -440.3359 AIC: 910.6717

Response: Spicy

(Intercept 1|2)

(Intercept 2|3)

(Intercept 3|4)

macer_mpf

macer_crio

temp_t30

saignée_yeS

macer_mpf:temp_t30

macer_crio:temp_t30

macer_mpf:saignée_yeS

macer_crio:saignée_yeS

temp_t30:saignée_yeS

macer_mpf:temp_t30:saignée_yeS

macer_crio:temp_t30:saignée_yeS

Variance of random effects: 3.820375

Log-likelihood: -370.3745 AIC: 770.749

Response: Reductive Flavour

(Intercept 1|2)

(Intercept 2|3)

$\begin{array}{cccc}\text { Estimate } & \text { Std. Error } & \boldsymbol{z} \text { value } & \text { p value } \\ & & & \\ -1.1386 & 0.4471 & -2.5468 & 0.0109 \\ 1.2060 & 0.4479 & 2.6926 & 0.0071 \\ 4.3321 & 0.5363 & 8.0782 & 0.0000 \\ 0.0499 & 0.4557 & 0.1096 & 0.9127 \\ 0.1608 & 0.4645 & 0.3462 & 0.7292 \\ -0.1525 & 0.4585 & -0.3326 & 0.7394 \\ 1.1519 & 0.4704 & 2.4487 & 0.0143 \\ -0.1498 & 0.6539 & -0.2292 & 0.8187 \\ -0.4033 & 0.6513 & -0.6192 & 0.5358 \\ -1.5589 & 0.6599 & -2.3623 & 0.0182 \\ -0.6185 & 0.6662 & -0.9285 & 0.3532 \\ -0.8154 & 0.6564 & -1.2424 & 0.2141 \\ 1.7148 & 0.9296 & 1.8446 & 0.0651 \\ 0.9283 & 0.9257 & 1.0028 & 0.3160\end{array}$

$\begin{array}{cccc}\text { Estimate } & \text { Std. Error } & \boldsymbol{z} \text { value } & \boldsymbol{p} \text { value } \\ & & & \\ -0.5564 & 0.6204 & -0.8969 & 0.3698 \\ 2.0614 & 0.6295 & 3.2745 & 0.0011 \\ 4.9503 & 0.7176 & 6.8980 & 0.0000 \\ -0.1852 & 0.5078 & -0.3646 & 0.7154 \\ 0.4977 & 0.4833 & 1.0297 & 0.3031 \\ -0.5353 & 0.4998 & -1.0710 & 0.2842 \\ -0.3292 & 0.4915 & -0.6698 & 0.5030 \\ -0.2278 & 0.7219 & -0.3155 & 0.7523 \\ -0.6648 & 0.7122 & -0.9335 & 0.3506 \\ 0.6800 & 0.7080 & 0.9603 & 0.3369 \\ -0.3624 & 0.6954 & -0.5211 & 0.6023 \\ 1.0832 & 0.7037 & 1.5394 & 0.1237 \\ -0.6528 & 1.0082 & -0.6475 & 0.5173 \\ 0.2113 & 1.0046 & 0.2103 & 0.8334\end{array}$

Estimate Std. Error z value pvalue

$\begin{array}{llll}1.6393 & 0.5385 & 3.0441 & 0.0023 \\ 3.5753 & 0.5663 & 6.3135 & 0.0000\end{array}$


(Intercept 3|4)

macer_mpf

macer_crio

temp_t30

saignée_yeS

macer_mpf:temp_t30

macer_crio:temp t30

macer_mpf:saignée_yeS

macer_crio:saignée_yeS

temp_t30:saignée_yeS

macer_mpf:temp_t30:saignée_yeS

macer_crio:temp_t30:saignée_yeS

Variance of random effects: 1.297362

Log-likelihood: -341.1959 AIC: 712.3919

Response: Volume

(Intercept 1|2)

(Intercept 2|3)

(Intercept 3|4)

macer_mpf

macer_crio

temp_t30

saignée yeS

macer_mpf:temp_t30

macer_crio:temp_t30

macer_mpf:saignée_yeS

macer_crio:saignée_yeS

temp_t30:saignée_yeS

macer_mpf:temp_t30:saignée_yeS

macer_crio:temp_t30:saignée_yeS

Variance of random effects: 2.452081

Log-likelihood: -363.6736 AIC: 757.3472

Response: Tannic Intensity

(Intercept 1|2)

(Intercept 2|3)

(Intercept 3|4)

macer_mpf

macer_crio

temp_t30

$\begin{array}{rrrr}5.6891 & 0.6864 & 8.2885 & 0.0000 \\ 0.4997 & 0.5912 & 0.8452 & 0.3980 \\ 0.8496 & 0.5730 & 1.4826 & 0.1382 \\ 0.4741 & 0.5916 & 0.8013 & 0.4230 \\ 0.3327 & 0.6012 & 0.5535 & 0.5799 \\ 0.7544 & 0.7995 & 0.9435 & 0.3454 \\ -0.9262 & 0.8043 & -1.1516 & 0.2495 \\ 0.5677 & 0.8007 & 0.7090 & 0.4783 \\ -0.4952 & 0.7995 & -0.6194 & 0.5357 \\ 1.0496 & 0.7944 & 1.3212 & 0.1864 \\ -2.4572 & 1.0868 & -2.2610 & 0.0238 \\ 0.3255 & 1.0936 & 0.2976 & 0.7660\end{array}$

Estimate Std. Error z value pvalue

$-2.4312$

$\begin{array}{lll}0.5641 & -4.3100 & 0.0000\end{array}$

$\begin{array}{llll}1.0280 & 0.5440 & 1.8898 & 0.0588\end{array}$

$\begin{array}{llll}5.3420 & 0.7100 & 7.5243 & 0.0000\end{array}$

$\begin{array}{llll}0.6751 & 0.4994 & 1.3518 & 0.1764\end{array}$

$\begin{array}{llll}-0.3829 & 0.5063 & -0.7561 & 0.4496\end{array}$

$\begin{array}{llll}0.6336 & 0.4956 & 1.2785 & 0.2011\end{array}$

$\begin{array}{llll}-0.1520 & 0.4958 & -0.3067 & 0.7591\end{array}$

$\begin{array}{llll}-0.9561 & 0.7015 & -1.3628 & 0.1729\end{array}$

$\begin{array}{llll}-0.0049 & 0.6996 & -0.0070 & 0.9944\end{array}$

$\begin{array}{llll}-0.8128 & 0.7008 & -1.1599 & 0.2461\end{array}$

$\begin{array}{llll}0.0190 & 0.7051 & 0.0269 & 0.9785\end{array}$

$\begin{array}{llll}0.2360 & 0.6968 & 0.3387 & 0.7348\end{array}$

$\begin{array}{llll}1.4665 & 0.9897 & 1.4818 & 0.1384\end{array}$

$\begin{array}{llll}-0.1187 & 0.9893 & -0.1200 & 0.9045\end{array}$

$\begin{array}{cccc}\text { Estimate } & \text { Std. Error } & \text { z value } & \text { p value } \\ & & & \\ -1.8768 & 0.5193 & -3.6138 & 0.0003 \\ 0.5701 & 0.5076 & 1.1232 & 0.2613 \\ 3.3761 & 0.5381 & 6.2747 & 0.0000 \\ 0.4639 & 0.4666 & 0.9943 & 0.3201 \\ 0.4117 & 0.4610 & 0.8932 & 0.3718 \\ 0.9988 & 0.4646 & 2.1498 & 0.0316\end{array}$


saignée yeS

macer_mpf:temp_t30

macer_crio:temp_t30

macer_mpf:saignée_yeS

macer_crio:saignée_yeS

temp_t30:saignée_yeS

macer_mpf:temp t30:saignée yeS

macer_crio:temp_t30:saignée_yeS

Variance of random effects: 2.151023

Log-likelihood: -444.2782 AIC: 918.5565

Response: Astringency

(Intercept 1|2)

(Intercept 2|3)

(Intercept 3|4)

macer_mpf

macer crio

temp_t30

saignée_yeS

macer_mpf:temp_t30

macer_crio:temp_t30

macer_mpf:saignée_yeS

macer_crio:saignée_yeS

temp_t30:saignée_yeS

macer_mpf:temp_t30:saignée_yeS

macer_crio:temp_t30:saignée_yeS

Variance of random effects: 1.278738

Log-likelihood: -462.8125 AIC: 955.6249

\section{Response: Dryness}

(Intercept 1|2)

(Intercept 2|3)

(Intercept 3|4)

macer_mpf

macer_crio

temp_t30

saignée_yeS

macer_mpf:temp_t30

macer_crio:temp_t30

macer_mpf:saignée_yeS

$\begin{array}{rrrr}0.5352 & 0.4684 & 1.1426 & 0.2532 \\ -0.4349 & 0.6690 & -0.6501 & 0.5157 \\ -0.8408 & 0.6538 & -1.2861 & 0.1984 \\ -0.4543 & 0.6556 & -0.6930 & 0.4883 \\ -0.6650 & 0.6481 & -1.0261 & 0.3048 \\ -0.4354 & 0.6616 & -0.6581 & 0.5104 \\ 0.3118 & 0.9442 & 0.3303 & 0.7412 \\ 1.4921 & 0.9263 & 1.6109 & 0.1072\end{array}$

Estimate Std. Error z value pvalue

$\begin{array}{llll}-3.2159 & 0.4859 & -6.6183 & 0.0000\end{array}$

$\begin{array}{llll}-0.2615 & 0.4380 & -0.5970 & 0.5505\end{array}$

$\begin{array}{llll}2.0096 & 0.4489 & 4.4768 & 0.0000\end{array}$

$\begin{array}{llll}-0.6006 & 0.4635 & -1.2960 & 0.1950\end{array}$

$\begin{array}{llll}0.5266 & 0.4516 & 1.1660 & 0.2436\end{array}$

$\begin{array}{llll}0.6423 & 0.4533 & 1.4170 & 0.1565\end{array}$

$\begin{array}{llll}-0.2390 & 0.4625 & -0.5166 & 0.6054\end{array}$

$\begin{array}{llll}0.1950 & 0.6481 & 0.3009 & 0.7635\end{array}$

$\begin{array}{llll}-1.0955 & 0.6415 & -1.7078 & 0.0877\end{array}$

$\begin{array}{llll}0.8691 & 0.6547 & 1.3275 & 0.1844\end{array}$

$\begin{array}{llll}-0.1178 & 0.6462 & -0.1823 & 0.8554\end{array}$

$\begin{array}{llll}-0.1130 & 0.6487 & -0.1742 & 0.8617\end{array}$

$\begin{array}{llll}-0.1932 & 0.9217 & -0.2096 & 0.8340\end{array}$

$\begin{array}{llll}1.0384 & 0.9094 & 1.1419 & 0.2535\end{array}$

$\begin{array}{cccc}\text { Estimate } & \text { Std. Error } & \boldsymbol{z} \text { value } & \boldsymbol{p} \text { value } \\ & & & \\ 0.4996 & -5.9272 & -0.0843 & 0.9328 \\ 0.4603 & 0.1848 & 2.4908 & 0.0127 \\ 0.4748 & 4.9201 & 0.0965 & 0.9231 \\ -0.4921 & 0.4608 & -1.0681 & 0.2855 \\ 0.3707 & 0.4558 & 0.8133 & 0.4161 \\ 0.3574 & 0.4575 & 0.7812 & 0.4347 \\ -0.2067 & 0.4675 & -0.4422 & 0.6584 \\ 0.6463 & 0.6500 & 0.9943 & 0.3201 \\ -0.8502 & 0.6475 & -1.3131 & 0.1891 \\ 0.2061 & 0.6582 & 0.3130 & 0.7542\end{array}$


macer_crio:saignée_yeS

$\begin{array}{llll}0.0598 & 0.6464 & 0.0926 & 0.9262 \\ 0.1573 & 0.6561 & 0.2398 & 0.8105 \\ 0.0255 & 0.9244 & 0.0276 & 0.9780 \\ 0.9680 & 0.9169 & 1.0557 & 0.2911\end{array}$

temp t30:saignée yeS

macer_mpf:temp_t30:saignée_yeS

macer_crio:temp_t30:saignée_yeS

0.9169

0.2911

Variance of random effects: 1.518573

Log-likelihood: -459.4391 AIC: 948.8782 